Research Article

\title{
Dietary Intake and Obesity among Filipino Americans in New Jersey
}

\author{
Persephone Vargas \\ William Paterson University, 300 Pompton Rd., Wayne, NJ 07470, USA \\ Correspondence should be addressed to Persephone Vargas; vargasp@wpunj.edu
}

Received 7 January 2018; Revised 29 May 2018; Accepted 13 July 2018; Published 16 September 2018

Academic Editor: Linda M. Gerber

Copyright ( 2018 Persephone Vargas. This is an open access article distributed under the Creative Commons Attribution License, which permits unrestricted use, distribution, and reproduction in any medium, provided the original work is properly cited.

\begin{abstract}
The prevalence of obesity is a public concern and is linked to chronic diseases. Filipino Americans have a high prevalence rate of hypertension and diabetes. This study investigated the dietary intake of first-generation Filipino Americans $(n=210)$. In addition, it provides a comparison of the obesity rates using the International guideline and the WHO Asian recommendation. The dietary intake included caloric, carbohydrate, and fat intake and was determined using the Block Brief Food Frequency Questionnaire. The anthropometric measurements included actual height, weight, and waist measurements. The body mass index (BMI) and waist circumference were categorized using the International guideline and the WHO Asian recommendation to determine obesity. The caloric and carbohydrate intake were normal; however, fat intake was increased. The BMI and waist circumference showed substantial difference when using the International and Asian guidelines to determine obesity. The results highlight the increased health risks of Filipino American immigrants including a high dietary fat intake and an increased obesity rate.
\end{abstract}

\section{Introduction}

In the United States, obesity is a public health concern with $34.9 \%$ of the adult population considered obese [1]. Overweight and obesity are major risk factors of chronic diseases such as hypertension (HTN), diabetes (DM), and cardiovascular disease (CVD) [2]. Obesity increases the risk for allcause CVD mortality [2]. It greatly impacts healthcare economy with the medical care cost of obesity estimated at $\$ 147$ billion [2].

The current U.S. guideline uses the WHO International classification to define obesity as a body mass index (BMI) of $\geq 30 \mathrm{~kg} / \mathrm{m}^{2}$ [3]. Using the International BMI measurement for obesity, Asian Americans have a low obesity rate (10.8\%) compared to all other races [1]. However, despite having a low obesity rate, Asians have a higher percentage of body fat compared to other races of the same age, sex, and BMI [4]. This results in Asians having a higher morbidity and mortality even with a lower BMI.

In 2004, the World Health Organization (WHO) expert consultation proposed lowering the BMI cut-off points for
Asians [4]. The WHO Asian BMI recommendation define overweight as a $B M I \geq 23 \mathrm{~kg} / \mathrm{m}^{2}$ to $<27.5 \mathrm{~kg} / \mathrm{m}^{2}$ and obesity as $\mathrm{BMI} \geq 27.5 \mathrm{~kg} / \mathrm{m}^{2}[4,5]$. In studies using the WHO Asian BMI cut-off, a significant increase in the overweight and obesity rates among the Asian American population was found $[6,7]$. A study using the WHO Asian BMI cut-off points showed that the Filipino American overweight/obesity rate (78.6\%) was higher than non-Hispanic Whites (53.8\%), African Americans (64.9\%), and Hispanics (69.7\%) [8]. In another study, the obesity rate for Filipino American men was 34.5\%, which was similar to the national obesity rate (34.9\%) [9].

Abdominal obesity is an indicator of visceral adiposity and is strongly associated with CVD and diabetes [10]. Waist circumference is a good predictor of abdominal fat and is related to increased all-cause mortality [10]. In the U.S., the waist circumference cut-off points follow the WHO waist circumference cut-off recommendation which considers substantially increased risk for waist circumferences $>35$ inches in women and $>40$ inches in men [11]. However, compared to Caucasians, Asians have a higher visceral fat [10]. This increased health risk despite lower waist 
circumference cut-off points warranted alternative cut-off points for the Asian population [10]. The recommended WHO Asian waist circumference cut-off points for increased health risks are $>31.5$ inches in women and $>35.5$ inches in men [9].

Diet plays an important role in obesity [2]. Excess calorie intake along with overconsumption of specific nutrients and foods such as saturated fat, added sugars, high sodium food, and refined grains contribute to obesity [2]. Studies on Filipino American diet have shown a change in the dietary intake of Filipino immigrants. This is consistent with dietary acculturation, the changes that occur in an immigrant's diet as they adopt to the dietary practices of the host country [12]. As early as 1975, a study on Filipino American diet had already shown an increase in caloric intake, with twice as many from protein (19\%), three times as many from fat intake (41\%), and half as many from carbohydrate intake (40\%) [13]. The most common dietary change noted among Filipino Americans is the increased consumption of meat and dairy [14]. Dietary acculturation is the change that occurs in an immigrant's diet as they adopt to the dietary practices of the host country [14]. Among Filipino Americans, Western dietary acculturation has been found to be correlated with a higher sugar, fat, and caloric intake $[15,16]$. Western dietary acculturation was also correlated with increased BMI and waist circumference $[15,16]$.

There is an estimated 3.9 million Filipinos in the United States, making them the second largest Asian subgroup [17]. Filipinos are also the second largest immigrant group, with 1.9 million (66\%) born outside of the U.S. [17]. New Jersey (NJ) ranks among the top five states in the U.S. with the most Filipino immigrants, with a Filipino population of 120,171 of which $75 \%$ are foreign-born [17]. Filipino Americans have an ideal sociodemographic profile with majority having a college degree, a significant number working as healthcare professionals, and a higher mean income [17].

Despite the ideal sociodemographic profile, the Filipino Americans suffer a concerning health disparity. Filipino Americans have significantly increased rates of chronic diseases such as cardiovascular disease (CVD), hypertension (HTN), diabetes (DM), and other CVD risk factors [18-21]. Studies have consistently reported the HTN prevalence rate in Filipino Americans as 53-59.9\% [18, 21], which is similar to the African Americans HTN prevalence rate. An analysis of the California Health Interview Survey revealed that the Filipino Americans had the highest BMI among all Asian American subgroups [20]. In addition, Filipino Americans had the second highest prevalence rate of diabetes, $15.8 \%$, second only to the Native Americans [20]. In comparison, the prevalence rate in the Philippines for diabetes is $5.9 \%$ [22], HTN is $22.3 \%$ [22], and obesity is $5.2 \%$ [23].

This article aims to present the dietary intake, including daily caloric, carbohydrate, and fat intake of Filipino Americans in New Jersey. This article also presents additional analysis of data that was previously reported in the International Journal of Environmental Research and Public Health [16]. The initial article presented the acculturation level and dietary pattern among first-generation Filipino American immigrants and the relationship among these variables with dietary-related health indicators. This current article provides a secondary analysis of the participants' BMI and waist circumference using the WHO Asian recommendation in comparison with the standard U.S. guidelines to determine obesity.

\section{Methods}

2.1. Study Design and Participants. A descriptive crosssectional study was conducted among first-generation Filipino Americans in New Jersey (NJ). The study included a convenience sample of adult Filipino Americans over the age of 18. All participants had to speak and read English. Pregnant women, those with medical condition that required a prescribed therapeutic diet, and those who had less than one year of residency in the U.S. were excluded from the study [16].

2.2. Procedures and Measures. Approval was obtained from the William Paterson University Institutional Review Board on May 20, 2014. Participants were recruited from Filipino organizations, churches, and festivals. Snacks were provided during data collection in the churches and organizations. A $\$ 10$ target gift card was provided as participation incentive during the Filipino festivals. All participants were asked to sign an informed consent prior to participation. All questionnaires were completed by the participants.

The participants' sociodemographic data and dietary intake were collected using pen and paper survey. Sociodemographic information included sex, age, immigration information, education, occupation, and income. To ensure anonymity, no identifying information was obtained.

The Block Brief Food Frequency Questionnaire (BFFQ) was used to estimate the participants' dietary intake. The BFFQ is a self-administered, 70-item questionnaire, developed from the National Health and Nutrition Examination Survey (NHANES) III dietary recall data [24]. It estimates the dietary intake of the most common foods. The completed questionnaires were sent to NutritionQuest for analysis. The nutritional variables for this study are daily caloric intake, carbohydrate intake, and fat intake.

Once the participants completed the questionnaires, anthropometric measurements were obtained including actual weight, height, and waist circumference. All anthropometric measurements were done by the author to ensure consistency.

The participants' height was measured using a portable stadiometer, to the nearest 0.1 inch (in.). Weight was measured using a digital weighing scale, to the nearest 0.1 pound (lb). All participants were measured with only one layer of clothing and were asked to remove their shoes. The participants' height and weight were used to calculate their BMI using the National Heart, Lung and Blood Institute (NHLBI) calculator [25].

The participants' waist circumference was measured using a nonstretchable measuring tape at the level of the umbilicus with the tape measure parallel to the floor. The 
measurement was obtained at the end of normal exhalation and rounded off to the nearest 0.5 inch.

The participants' BMI and waist circumference measurements were evaluated using both the standard guidelines and the WHO Asian recommendation. The International guideline defines overweight as having a $\mathrm{BMI} \geq 25$ to $\leq 30$ and obesity as having a BMI $\geq 30$ [2]. Using the WHO Asian BMI cut-off, the categories are normal (BMI 18.5 to $<23$ ), overweight $(\mathrm{BMI} \geq 23$ to $<27.5)$, and obese $(\mathrm{BMI} \geq 27.5)[3,4]$. For the waist circumference, the International guideline cut-off points for increased health risks are $>35$ inches in women and $>40$ inches in men [10]. Using the WHO Asian cut-off, the waist circumference cut-off points for increased health risks are $>31.5$ inches in women and $>35.5$ inches in men [10].

2.3. Analysis of Data. All data collected were entered and computed using SPSS 21. Descriptive statistics were used to summarize sociodemographic data, nutritional intake, BMI, and waist circumference. The BMI categories and the waist circumference categories were calculated for both the International guideline and the WHO Asian recommendation. Pearson's correlation was used to investigate the relationship between sociodemographic factors, dietary intake, and anthropometric measurements. A value of $p<0.05$ was considered statistically significant.

\section{Results}

A total of 210 Filipino Americans were recruited to participate in the study. The sociodemographic information, as previously reported [16], included age, sex, marital status, education, occupation, and immigration data. The mean age of participants was $46.6(\mathrm{SD}=13.6)$ ranging from 18 to 74 years. One hundred thirty-four $(63.8 \%)$ of the respondents were female and $76(36.2 \%)$ were male. Majority of the respondents were married $(74.3 \%)$, had a college degree or higher $(81.9 \%)$, and were currently employed $(76.7 \%)$. The most common occupation was in health care with $38.1 \%$ working as a healthcare professional. Most participants had an individual income of $\$ 50,000$ or above $(55.7 \%)$, with the largest percentage of participants earning \$75,000-99,999 $(21.9 \%)$.

Immigration information included the length of residency in the U.S. and age of immigration. The length of residency in the U.S. ranged from 1 to 49 years with a mean of 17.6 years $(S D=9.2)$. The age upon immigration ranged from 1 to 62 years old, with a mean of 28.62 years $(S D=11.8)$ [16].

Table 1 presents the dietary intake of the participants. The mean daily caloric intake was $1513.2 \mathrm{kcal}(\mathrm{SD}=723.3)$, mean fat intake was $35.2 \%(\mathrm{SD}=7.7)$, and mean carbohydrate intake was $50.2 \%(\mathrm{SD}=9.1)$. When analyzed by gender, the mean caloric intake for men is $1,648.6 \mathrm{kcal}(\mathrm{SD}=739.1)$, fat intake was $34.6 \%(\mathrm{SD}=7.6)$, and carbohydrate intake was $50.8 \%(\mathrm{SD}=9.3)$ [21]. The mean caloric intake for the women was $1,436.5 \mathrm{kcal}(\mathrm{SD}=705.4)$, fat intake was $35.5 \%$ (7.7), and carbohydrates was 50.1\% $(\mathrm{SD}=9)$.

The relationship between dietary intake (caloric intake, fat intake, and carbohydrate intake), age, immigration
TABLE 1: Dietary intake.

\begin{tabular}{lccc}
\hline Participants & $\begin{array}{c}\text { Caloric } \\
\text { intake } \\
(\text { kcal })\end{array}$ & $\begin{array}{c}\text { Carbohydrate } \\
\text { intake }(\%)\end{array}$ & $\begin{array}{c}\text { Fat intake } \\
(\%)\end{array}$ \\
\hline Men & 1648.6 & 50.8 & 34.6 \\
Women & 1436.5 & 49.9 & 35.5 \\
Total & 1513.2 & 50.2 & 35.2 \\
\hline
\end{tabular}

status (length of residency and immigration age), and sociodemographic data (gender, marital status, education, occupation, and income) was investigated. There were no significant relationships found between dietary intake and sociodemographic data. The correlations between dietary intake, age, length of residency in the U.S., and immigration age are presented in Table 2. Age was found to be significantly correlated with carbohydrate intake $(r=0.212$, $p<0.05)$ : those who were older had a higher carbohydrate intake. A negative correlation was found between immigration age and fat intake $(r=-1.158, p<0.05)$ : those who migrated at an older age had lower fat intake. A significant correlation was also found between immigration age and carbohydrate intake $(r=0.2458, p<0.001)$ : those who migrated at an older age had a higher carbohydrate intake.

The participant's mean BMI was $25.4(\mathrm{SD}=3.6)$ [16]. When analyzed by gender, the male participants' mean BMI was $26.7(\mathrm{SD}=4.1)$ and the female participants' mean BMI was $24.7(\mathrm{SD}=3.2)[16]$. The participants' BMI was categorized as normal, overweight, and obese using both the International guideline and the WHO Asian BMI recommendation. Table 3 shows a comparison of the BMI categories between the International guideline and the WHO Asian recommended BMI cut-off. In men, the obesity rate doubled while in women there was more than a threefold increase when the WHO Asian BMI was used to determine obesity.

The male mean waist circumference was 35.9 inches $(\mathrm{SD}=4.8)$. The female mean waist circumference was 32.3 inches $(\mathrm{SD}=3.7)$ [16]. Table 4 shows a comparison of the waist circumference categories between the International guideline and the WHO Asian recommendation. In both men and women, those classified with increased risk more than doubled when using the WHO Asian waist circumference cut-off.

The relationship between anthropometric measurements and sociodemographic factors was investigated. There were no statistically significant differences noted in BMI when compared by sex, marital status, education, income, or occupation. An analysis of the correlation between age and immigration status showed a significant correlation between age and waist circumference $(r=0.282, p<0.001)$ : those who were older had an increased waist circumference and WHR. There was also a significant correlation between immigration age and waist circumference $(r=0.275, p<0.001)$ : those who came to the U.S. at an older age had an increased waist circumference.

\section{Discussion}

This study highlights the significant difference between the International BMI guideline and the WHO Asian BMI recommendation to determine obesity in the Filipino American 
TABLE 2: Correlations between dietary intake, age, and immigration information.

\begin{tabular}{lccc}
\hline $\begin{array}{l}\text { Dietary } \\
\text { intake }\end{array}$ & Age & $\begin{array}{c}\text { Length of } \\
\text { residency }\end{array}$ & $\begin{array}{c}\text { Immigration } \\
\text { age }\end{array}$ \\
\hline Calories & $-0.043(0.536)$ & $-0.124(0.072)$ & $0.050(0.471)$ \\
\hline Fat & $-0.122(0.78)$ & $0.033(0.639)$ & $-1.158^{*}(0.022)$ \\
\hline Carbohydrate & $0.212^{*}(0.002)$ & $-0.009(0.892)$ & $0.246^{*}(<0.001)$ \\
\hline
\end{tabular}

${ }^{*}$ Findings that reached statistical level. Significance established at $p<0.05$.

TABLE 3: Comparison of BMI categories using the International guideline and the WHO Asian recommendation.

\begin{tabular}{lcc}
\hline BMI category & International BMI guideline & WHO Asian BMI \\
\hline Overall & & \\
Normal (\%) & 54.3 & 25.2 \\
Overweight (\%) & 36.2 & 49.5 \\
Obese (\%) & 9.5 & 25.2 \\
\hline Men & & \\
Normal (\%) & 38.2 & 13.2 \\
Overweight (\%) & 46.1 & 55.3 \\
Obese (\%) & 15.8 & 31.6 \\
\hline Women & & \\
Normal (\%) & 63.4 & 32.1 \\
Overweight (\%) & 30.6 & 46.3 \\
Obese (\%) & 6 & 21.6 \\
\hline
\end{tabular}

TABle 4: Comparison of waist circumference categories using the International guideline and the WHO Asian recommendation.

\begin{tabular}{lcc}
\hline $\begin{array}{l}\text { Waist } \\
\text { circumference } \\
\text { category }\end{array}$ & $\begin{array}{c}\text { International waist } \\
\text { circumference cut-off }\end{array}$ & $\begin{array}{c}\text { WHO Asian waist } \\
\text { circumference cut-off }\end{array}$ \\
\hline $\begin{array}{l}\text { Men } \\
\text { Normal (\%) }\end{array}$ & 80.3 & 50 \\
$\begin{array}{l}\text { Increased risk } \\
(\%)\end{array}$ & 19.7 & 50 \\
\hline $\begin{array}{l}\text { Women } \\
\text { Normal (\%) } \\
\begin{array}{l}\text { Increased risk } \\
(\%)\end{array}\end{array}$ & 76.1 & 49.3 \\
\hline
\end{tabular}

population. When using the WHO Asian BMI recommendation, there was a significant increase in the overweight and obesity rates of the participants. The number of participants with an increased waist circumference indicating increased health risks was also significantly higher when using the WHO Asian waist circumference cut-off points.

The results of this study indicate an overwhelming underestimation of obesity and abdominal obesity in the Filipino Americans when using the International BMI and waist circumference guidelines. In total, the obesity rate increased from $9.5 \%$ to $25.2 \%$ when using the WHO Asian BMI cut-off. The obesity rate in men was doubled $(15.8 \%$ to $31.6 \%$ ), and the obesity rate in women increased more than threefold (6\% to $21.6 \%$ ) when using the WHO Asian BMI cut-off points [21]. For the waist circumference, half of the participants exceeded the WHO Asian waist circumference cut-off points, indicating increased health risks.
Ursua et al. [21] had similar findings with the Filipino Americans in the New York area. The study also used both the International guideline and WHO Asian recommendation to categorize BMI. Using the International guideline, $48.4 \%$ of the participants had a normal BMI and $51.6 \%$ were overweight or obese. However, using the WHO Asian BMI cut-off, $25.5 \%$ of the participants had a normal BMI and $74.5 \%$ were overweight or obese. The study did not categorize BMI according to gender and did not use waist circumference.

Other studies have used both the International guideline and the WHO Asian recommendation to categorize the BMI of Filipino American immigrants. In using the International BMI guideline, the other studies have shown that anywhere from 44 to $66 \%$ of Filipino Americans are overweight or obese. However, these numbers become more concerning when categorized using the WHO Asian recommendation, with $60-80 \%$ in the overweight or obese category $[6,8,26]$.

Filipino Americans have been found to have significantly higher visceral adiposity compared to Caucasians and African Americans [27]. Increased BMI and waist circumference have been linked to increased risk for cardiovascular disease, diabetes, other chronic diseases, and mortality. Asians have a higher risk for metabolic disease, diabetes, and cardiovascular disease compared to Caucasians with BMI $\left(25 \mathrm{~kg} / \mathrm{m}^{2}\right)$ and waist circumference (40 inches in men, 35 inches in women) below the existing cut-off points $[4,10]$. Thus, it is important to use the appropriate guideline in determining obesity for this population.

Another important finding of the study is the increased fat intake among the participants. The mean daily caloric intake $($ women $=1,436.5 \mathrm{kcal}$, $\operatorname{men}=1,648.6 \mathrm{kcal}$ ) in this study was lower than the recommended dietary guidelines (women $=1,600-2,400 \mathrm{kcal}$, men $=2,000-3,000 \mathrm{kcal}$ ) [28], and the carbohydrate intake was within the normal range (50.2\%) of the dietary recommendation (45-65\%) [28]. However, the fat intake (35.2\%) was above the dietary recommendations (20-35\%) [28]. It is important to note that more than half (52\%) of the participants had a fat intake greater than the dietary recommendation.

The finding of increased mean fat intake in this study is consistent with the other studies on Filipino American diet. The most common dietary change that occurs when Filipinos immigrate to the U.S. is the increased consumption of meat and fat $[12,14-16]$. The studies indicated that the participants consumed more beef, pork, chicken, dairy products, and fast foods. This dietary change is mostly due to the availability and affordability of these types of food [14]. In comparison, the average diet of Filipinos in the Philippines, according to the Philippine Food and Nutrition Research Institute, consists of rice, fish, vegetables, chicken, and fruits [29]. Rice represents $42 \%$ of the total average daily intake, vegetables $13 \%$, fish $12 \%$, fruits $9 \%$, and meat and poultry $6 \%$ [29]. The increase in fat intake among Filipino Americans is a health concern since it is a risk factor for several chronic diseases including CVD and DM.

Rice remains the staple food of Filipino American immigrants and the major source of carbohydrates [13, 14, 30]. In addition to rice, Filipino Americans also eat more bakery products [14]. The study also showed an increase in carbohydrate intake among the older participants and those 
who migrated at an older age, and a decrease in fat intake in those who migrated to the U.S. at an older age. It is plausible that the older participants and those who migrated at an older age are used to having rice with each meal, which is traditional [14]. They may have not have adapted to the Westernization of diet which can lead to a decrease in rice and carbohydrate intake and increase in fat intake $[15,16]$.

There is a concern that the use of the food frequency questionnaire may lead to underestimation of dietary intake since it does not include commonly eaten traditional food or reflect dietary practices [30]. Quantifying food intake frequency and amount becomes a challenge because Filipino Americans tend to serve meals family-style. The participants have the tendency to base their answers on what their family ate and felt guilty when they thought about how much they ate [30]. This may explain the low caloric intake finding in the study. To improve the accuracy of dietary intake measurement among Filipino immigrants, an FFQ to reflect Filipino dietary practices should be considered.

It is important to note that the sociodemographic factors did not show a statistically significant difference in the dietary intake, BMI, and waist circumference. This result is similar to the findings by Serafica et al. [15]. The Filipino American immigrants have an ideal sociodemographic profile: majority of them have a college degree, work in the healthcare field, and have a higher income [17]. However, these sociodemographic factors did not improve the dietary intake or the anthropometric findings in this population. These findings show that all Filipino Americans regardless of socioeconomic status have increased health risk factors.

To the best of the author's knowledge, this is the first study that investigated the dietary intake of Filipino Americans in the Northeast area. Only one other study examined the BMI of Filipino American in the NY/NJ area [21]. The study utilizes actual anthropometric measurements, instead of self-reported measurements.

The study has some limitations that should be taken into consideration. The use of a convenience sample and the sample size limit the generalization of the findings. The participants filled out their own surveys rather than by an interviewer. As with most dietary studies, this study relied on the dietary information provided by the participants: the frequency and amount of food consumption may not be precise. Additionally, the BFFQ may not represent food items the participants were consuming.

\section{Conclusion}

The study highlights the difference in the overweight and obesity rates among Filipino Americans when using the WHO Asian cut-off points compared to the International guideline. The continued use of the International guideline to determine obesity in the Filipino American population will mask the health risks in this population and delay primary prevention. It is necessary for the healthcare providers to utilize the WHO Asian recommendation for BMI and waist circumference cut-off points to improve prevention and provide early detection and treatment of cardiovascular and metabolic diseases.
The study also confirms an increased fat intake among Filipino Americans. With the increased prevalence rates of HTN and diabetes among the Filipino Americans $[18-20,31]$, there is a need for targeted interventions on improving dietary intake in this high-risk group. Future studies should include culturally competent interventions in improving dietary fat intake and decreasing obesity.

\section{Data Availability}

The data used to support the findings of this study are available from the corresponding author upon request.

\section{Conflicts of Interest}

The author declares that there are no conflicts of interest regarding the publication of this paper.

\section{Acknowledgments}

The author would like to thank Jade Misajon for her assistance with reviewing this manuscript. This article is part of the author's dissertation: P. Vargas, Acculturation, Dietary Acculturation and Health Indicators among Filipino Americans in New Jersey, ProQuest Dissertations \& Theses Global (1655594732), 2015, http://ezproxy.wpunj. edu:2048/login?url=http://search.proquest.com/docview/ 1655594732 ? accountid=15101.

\section{References}

[1] C. L. Ogden, M. D. Carroll, B. K. Kit, and K. M. Flegal, "Prevalence of childhood and adult obesity in the United States, 2011-2012," Journal of the American College of Cardiology, vol. 311, no. 8, pp. 806-811, 2014.

[2] M. D. Jensen, D. H. Ryan, C. M. Apovian et al., "2013 AHA/ ACC/TOS guideline for the management of overweight and obesity in adults," Journal of the American College of Cardiology, vol. 63, no. 25, pp. 2985-3023, 2017.

[3] National Heart, Lung and Blood Institute, Identification, Evaluation, and Treatment of Overweight and Obesity in Adults, NIH Publication, Bethesda, MD, USA, 2000.

[4] World Health Organization Expert Consult, "Appropriate body-mass index for Asian populations and its implications for policy and intervention strategies," The Lancet, vol. 363, no. 9403, pp. 157-163, 2004.

[5] R. Oza-Frank, M. K. Ali, V. Vaccarino, and K. M. V. Narayan, "Asian Americans: diabetes prevalence across U.S. and World Health Organization weight classifications," Diabetes Care, vol. 32, no. 9, pp. 1644-1646, 2009.

[6] J. Lee, F. Brancati, and H. Yeh, "Trends in the prevalence of type 2 diabetes in Asians and Whites," Diabetes Care, vol. 34, pp. 353-357, 2011.

[7] S. S. Yi, S. C. Kwon, L. Wyatt, N. Islam, and C. Trinh-Shevrin, "Weighing-in on the hidden Asian American obesity epidemic," Preventive Medicine, vol. 73, pp. 6-9, 2015.

[8] J. Jih, A. Mukherjea, E. Vittinghoff et al., "Using appropriate body mass index cut points for overweight and obesity among Asian Americans," Preventive Medicine, vol. 65, pp. 1-6, 2014.

[9] P. Mui, J. V. Bowie, H.-S. Juon, and R. J. Thorpe, "Ethnic group differences in health outcomes among Asian American 
men in California," American Journal of Men's Health, vol. 11, no. 5, pp. 1406-1411, 2017.

[10] World Health Organization, Waist Circumference and WaistHip Ratio: Report of an Expert Consultation, World Health Organization, Geneva, Switzerland, 2011.

[11] National Heart, Lung and Blood Institute, "How are overweight and obesity diagnosed?," July 2012, http://www.nhlbi. nih.gov/health/health-topics/topics/obe/diagnosis.html.

[12] J. Satia-Abouta, "Dietary acculturation: definition, process, assessment, and implications," International Journal of $\mathrm{Hu}$ man Ecology, vol. 4, no. 1, pp. 71-86, 2003.

[13] J. Lewis and M. Glaspy, "Food habits and nutrient intakes of Filipino women in Los Angeles," Journal of the American Dietetic Association, vol. 67, no. 2, pp. 122-125, 1975.

[14] F. A. Dela Cruz, B. T. Lao, C. Heinlein et al., "Level of acculturation, food intake, dietary changes, and health status of first-generation Filipino Americans in Southern California," Journal of American Association of Nurse Practitioner, vol. 25, no. 11, pp. 1-12, 2013.

[15] R. Serafica, S. H. Lane, and C. D. Ceria-Ulep, "Dietary acculturation and predictors of anthropometric indicators among Filipino Americans," SAGE Open, vol. 3, no. 3, pp. 1-15, 2013.

[16] P. Vargas and L.-F. Jurado, "Dietary acculturation among Filipino Americans," International Journal of Environmental Research and Public Health, vol. 13, no. 1, pp. 1-11, 2016.

[17] US Census, "Profile of general population," American Fact Finder, https://factfinder.census.gov/faces/tableservices/jsf/pages/ productview.xhtml?pid=ACS_16_1YR_S0201\&prodType=table.

[18] B. Zhao, P. O. Jose, J. Pu et al., "Racial/ethnic difference in hypertension prevalence, treatment and control for outpatients in Northern California," American Journal of Hypertension, vol. 28, no. 5, pp. 631-639, 2015.

[19] S. E. Choi, M. Liu, L. P. Palaniappan, E. J. Wang, and N. D. Wong, "Gender and ethnic differences in the prevalence of type 2 diabetes among Asian subgroups in California," Journal of Diabetes Complications, vol. 27, no. 5, pp. 429-435, 2013.

[20] M. Shih, Y. Du, A. S. Lightstone, P. A. Simon, and M. C. Wang, "Stemming the tide: rising diabetes prevalence and ethnic subgroup variation among Asians in Los Angeles County," Preventive Medicine, vol. 63, pp. 90-95, 2014.

[21] R. Ursua, N. Islam, D. Aguilar et al., "Predictors of hypertension among Filipino immigrants in the Northeast U.S," Journal of Community Health, vol. 38, no. 5, pp. 847-855, 2013.

[22] Food and Nutrition Research Institute, "8th National Nutrition Survey 2013," http://www.nnc.gov.ph/.

[23] A. Litonjua, "Population trends \& obesity patterns in the Philippines: a window to the obesity epidemic in the AsiaOceania Region," Journal of the ASEAN Federation of Endocrine Societies, vol. 26, no. 2, pp. 141-142, 2011.

[24] NutritionQuest, n.d., "Questionnaires and screeners," https:// nutritionquest.com/assessment/list-of-questionnaires-andscreeners/.

[25] National Heart, Lung and Blood Institute, "Calculate your body mass index," https://www.nhlbi.nih.gov/health/educational/lose_ wt/BMI/bmicalc.htm.

[26] A. E. Maxwell, C. M. Crespi, R. E. Alano, M. Sudan, and R. Bastani, "Health risk behaviors among five Asian American subgroups in California: identifying intervention priorities," Journal of Immigrant and Minority Health, vol. 14, no. 5, pp. 890-894, 2012.
[27] M. Araneta and E. Barrett-Connor, "Ethnic differences in visceral adipose tissue and type 2 diabetes: Filipino, African Americans and Whites," Obesity Research, vol. 13, no. 8, pp. 1458-1465, 2005.

[28] U.S. Department of Agriculture and U.S. Department of Health and Human Services, Dietary Guidelines for Americans, U.S. Government Printing Office, Washington, DC, USA, 7th edition, 2010.

[29] E. Natera, T. Trinidad, D. Valdez, H. Kawamura, L. Palad, and K. Shiraishi, "Estimation of micronurient intake of Filipinos," Food and Nutrition Bulletin, vol. 23, no. 3, pp. 222-227, 2002.

[30] M. Johnson-Kozlow, G. Matt, C. Rock, R. dela Rosa, T. Conway, and R. Romero, "Assessment of dietary intakes of Filipino-Americans: implications of food frequency questionnaire design," Journal of Nutrition Education and Behavior, vol. 43, no. 6, pp. 505-510, 2011.

[31] J. Ye, G. Rust, P. Baltrus, and E. Daniels, "Cardiovascular risk factors among Asian Americans: result from a National Health Survey," Annals of Epidemiology, vol. 19, no. 10, pp. 718-723, 2009. 


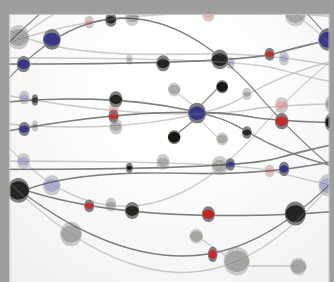

The Scientific World Journal
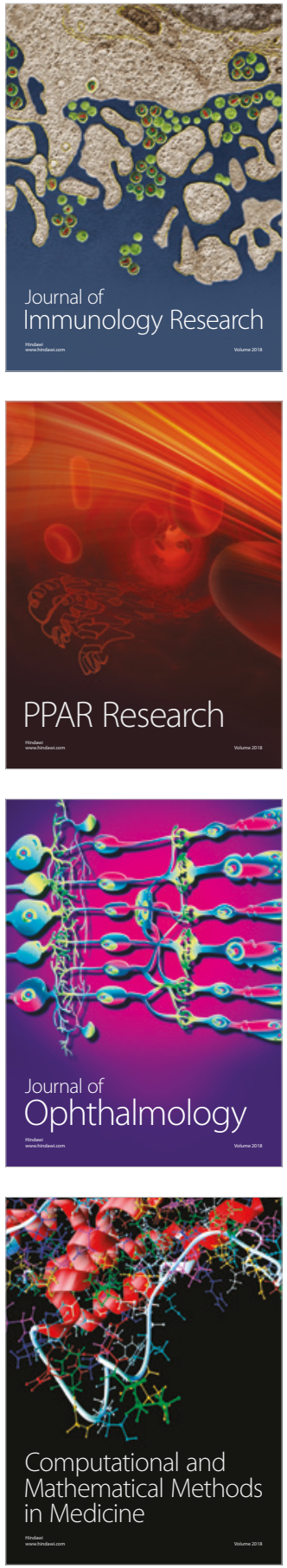

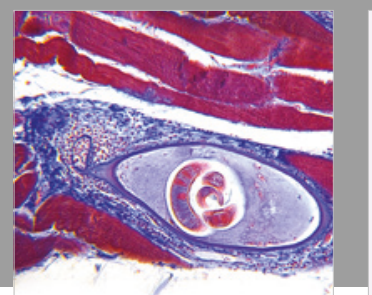

Gastroenterology Research and Practice

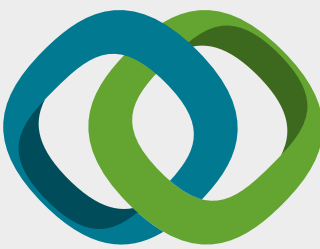

\section{Hindawi}

Submit your manuscripts at

www.hindawi.com
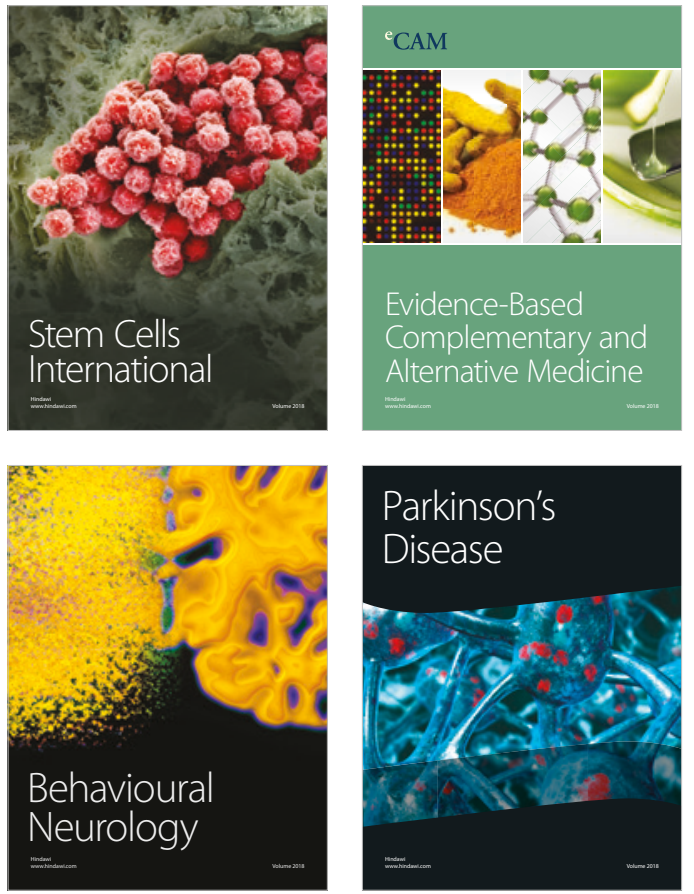

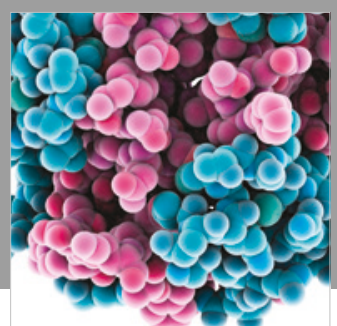

ournal of

Diabetes Research

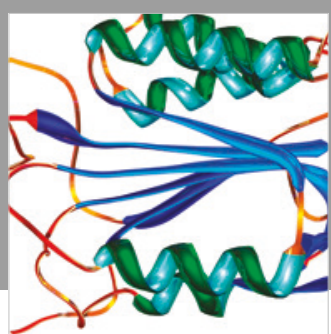

Disease Markers
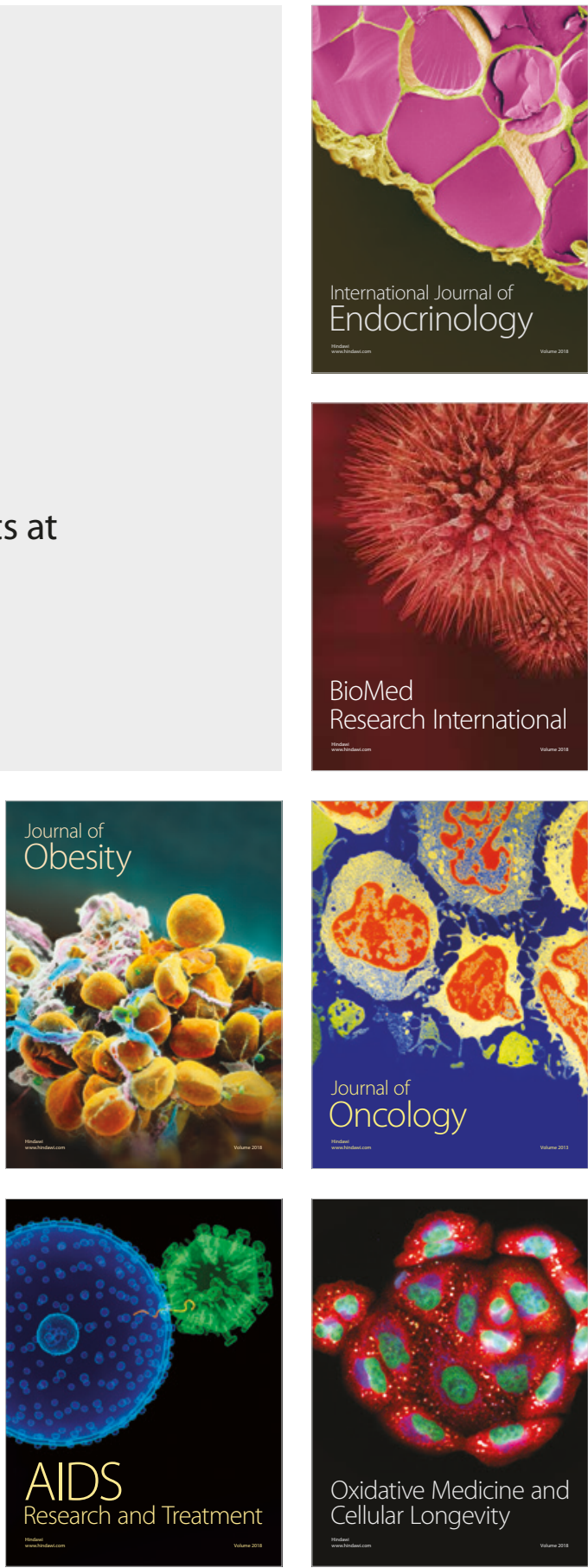